\title{
Эмпирическое исследование факторов, определяющих инвестиционную активность российских компаний
}

\begin{abstract}
Теплова Т.В. ${ }^{3}$, Крылова М.С. ${ }^{4}$
В статье систематизированы перспективные направления эмпирических исследований инвестиционного поведения компаний на развивающихся рынках. Особое внимание уделено выявлению фундаментальных факторов, оказывающих влияние на инвестиционную активность. Показань результаты проведенного эмпирического исследования фундаментальных и нефундаментальных (структура собственности) детерминант инвестиций в реальные и финансовые активы крупнейших публичных компаний РФ. Сделан вывод о различии детерминант капитальных вложений и долгосрочных финансовых инвестиичии.
\end{abstract}

\section{Перспективные направления исследования инвестиционного поведения компаний}

Трудный и длительный период реформирования экономики с целью перехода на рыночные рычаги управления породил ряд проблем, имеющих существенное влияние на будущее развитие экономики, а также благосостояние и безопасность жизни населения. Одна из проблем касается крайней степени износа внеоборотных материальных активов. Одна из часто дискутируемых проблем в процессах обновления внеоборотных активов - недостаточность источников финансирования, дорогой заемный капитал, невозможность привлечь в достаточном количестве собственный. Актуальный для российской экономики предмет исследования - насколько инвестиционные решения зависимы от внутренне генерируемых денежных средств. Какие ограничения возникают у российских компаний в реализации инвестиционной деятельности?

Вторая проблема связана со слабыми рычагами мотивации инновационной активности, низкими стимулами к инвестициям в интеллектуальный капитал, включая бренды, торговые марки, научные исследования и разработки. Российские компании только нащупывают, часто интуитивно, рычаги максимизации стоимости, и среди них инвестиционные. Эмпирических исследований, проверяющих действенность тех или иных рычагов в условиях российских реалий,

\footnotetext{
${ }^{3}$ Теплова Тамара Викторовна, доцент кафедры «Экономика и финансы фирмы», ГУ ВШЭ, старший научный сотрудник научно-учебной лаборатории «Корпоративные финансы», д.э.н. ${ }^{4}$ Крылова Марина Сергеевна - студентка 5-го курса факультета экономики.
} 
крайне мало. Практически неизученными остались вопросы нефундаментальных детерминант инвестиционного поведения в ситуации развивающихся рынков с асимметрией информации, страновыми рисками и низкой ликвидностью фондового рынка.

Представляется, что в инвестиционном поведении российских компаний важен анализ трех принципиально различных направлений инвестирования

1. Инвестиции в модернизацию, расширение существующего основного капитала, представленного материальными внеоборотными активами. Традиционный термин, применяемый для этого направления инвестиционной деятельности компании, - капитальные вложения (capital expenditure, capital budgeting, CAРЕХ). Это направление инвестирования характеризует стратегию внутреннего роста.

2. Финансовые инвестиции, представленные вложениями в доли других компаний на рынке и позволяющие реализовывать стратегии внешнего роста через интеграционное или конгломератное поглощение. В англоязычной литературе для этого направления используется следующее обозначение - Long Term Investment (LTI).

3. Интеллектуальные инвестиции, или инвестиции в интеллектуальный капитал, который может рассматриваться как часть основного капитала компании. Сложность исследования этого направления инвестирования связана с узостью представления интеллектуального капитала в стандартной финансовой отчетности. В стандартизированном финансовом учете распознается и фиксируется под термином «нематериальные активы» (intangible assets) лишь часть ресурсов, которые действительно создают будущие денежные поступления компании, и, следовательно, генерируют рост стоимости вложенного капитала. Это направление инвестирования очень слабо изучено и представлено в научной литературе.

Рассматривая инвестиционное поведение российских компаний, мы видим три направления перспективных эмпирических исследований. Вопервых, регуляторная роль рынка. Насколько созрел фондовый рынок в России, чтобы выступать индикатором качества реализуемых инвестиционных программ, например как на рынке США [Barro, 1990]? Распознает ли рынок направления инвестирования? Учитывает ли инвестиции в интеллектуальный капитал (как в исследовании Чена [Chan, 2001]). Отсекает ли «фондовые пузыри» [Chirinko, 1996]; [Gilchrist, 2005] при рассмотрении реальных инвестиций? Ключевым индикатором в этом направлении выступает рыночная оценка компании (рыночная капитализация), а точнее ее нормированный показатель. Часто в качестве такого нормированного показателя выступает коэффициент Q Тобина, рассчитанный как отношение рыночной капитализации к балансовой оценке собственного капитала (MV/BE). 
В рамках этого направления может исследоваться и обратное влияние фондового рынка на решения менеджеров. Насколько менеджеры компаний учитывают в принятии инвестиционных решений оценку рынком перспектив развития отрасли или данной компании по показателю Q Тобина. На развитых рынках проведено множество исследований влияния фондового рынка на принятие решений в компаниях [Schaller, 1990]; [Bond, 1992]; [Gugler, 2004]. На развивающихся рынках этот вопрос остается открытым и требует изучения. Заметим, что выбор мультипликатора «рыночная/балансовая стоимость» является не бесспорным для диагностирования инвестиционных возможностей («возможностей роста», как часто трактуется в академической литературе). В ряде исследований (например, [Shiantarelli, 1989]) показано, что этот фактор значим только для крупных компаний рынка. Большинство исследователей утверждают, что влияние фондового рынка не очень существенно при рассмотрении разнородной выборки. Например, для развитых рынков в краткосрочном периоде 10\%-ный рост рыночной стоимости акции приводит только к 2,5\%-ному росту инвестиций [Bond, 1992].

Второе направление перспективных исследований видится нам в анализе влияния на инвестиционное поведение различных рыночных и специфических для компании факторов. Прежде всего речь идет о факторах неопределенности и их представлении в виде оцененных индикаторов риска [Ferderer, 1993]; [Leahy, 1996]; [Ghosal, 1996]; [ $\underline{\text { Bulan, }}$ 2005]. Насколько рыночный риск значим для принятия разнонаправленных инвестиционных решений в компании и как оценивать рыночный риск? Например, для рынка Германии [Kalckreuth, 2000] показано, что эффекты воздействия волатильности цен на сырье и материалы, с одной стороны, и на производимые товары, с другой, (input and output prices) одинаковы и составляют чуть больше $3 \%$, т.е. при увеличении показателей волатильности на одно стандартное отклонение инвестиции снижаются на 6,5 \%. Насколько рыночный риск определяет инвестиционное поведение российских компаний, значимы ли факторы специфического риска?

Так как существенную долю инвестиционных оттоков компаний составляют реальные инвестиции (в создание материальных активов), которые так часто являются необратимыми, что актуален вопрос об использовании опционных возможностей. Степень задействования прав позволяет отложить инвестиции или изменить их масштаб при росте неблагоприятных рыночных факторов на российском рынке - и это еще одна область исследований значимых (фундаментальных) факторов, которая нашла отражение в ряде академических исследований развитых рынков [Jeon, 2004], [Bulan, 2005]. Ключевой вопрос исследования - как компании меняют инвестиционное поведение при подвижках на рынке (росте процентной ставки, инфляции, изменениях в валютном, налоговом 
регулировании), а также при ухудшении финансовых показателей, например при падении прибыли и операционного денежного потока. Одно из направлений в этом блоке - поведение прямых иностранных инвестиций (FDI). В работе [Jeon, 2004] исследуется влияние общерыночного глобального риска и отсутствие информации по специфике функционирования локального рынка Кореи на FDIза период с 1962-го по 2001 год. Авторы пытаются эмпирически оценить стоимость временного (timing) опциона (на отсрочку инвестиций), учитывая политические, экономические и другие факторы неопределенности. Анализируются факторы, объясняющие временной лаг между моментом получения разрешения на инвестиции и их реальным началом осуществления. Показано, что такие факторы, как предыдущий опыт работы на корейском рынке, принадлежность страны-инвестора к Азиатскому региону (следовательно, социокультурные традиции), изначально высокая доля иностранного капитала в компании сокращают временной лаг. Интересно отметить, что в период после азиатского кризиса (1997) лаг увеличивается.

Еще одно перспективное направление исследования влияния фундаментальных факторов - чувствительность инвестиционной активности к наличию внутренних источников (прибыли и операционного денежного потока). Существенный вопрос для исследования в рамках этого направления - могут ли финансовые решения и финансовая деятельность по привлечению нового капитала сгладить негативные результаты текущей (основной) деятельности на инвестиционную активность [Hayashi, 1985]. Насколько зависимы будут инвестиции от снижения/роста операционных денежных потоков [Tybout, 1983], [Fazzari, 1988]?

Зависимость инвестиций от внутренних источников финансирования проявляется при наличии финансовых ограничений (financial constraints), под которыми в традиционной трактовке понимается наличие существенных различий в затратах на капитал по внутренним (прибыль) и внешним (дополнительная эмиссия акций, новый заемный, например, публичный, капитал) источникам финансирования. Чем более несовершенен финансовый рынок и сильнее проявления агентских конфликтов, тем существеннее для компании становятся ограничения в привлечении нового собственного и заемного капитала [Moyen, 2004]. Финансовые ограничения также существенно связаны со степенью развития правовой среды, с защитой интересов различных владельцев капитала. В работе Гаглера [Gugler,2004] эмпирическое исследование доказывает, что в странах с англо-саксонской правовой системой (common law) (США, Великобритания, Канада, Австралия) инвестиционные решения принимаются более эффективно, чем в странах с континентальным правом (civil law). 
Часто в качестве прокси-переменной финансовой ограниченности на развитых рынках выступает показатель дивидендных выплат. Чем выше дивидендный выход, тем меньше финансовых ограничений для компании можно предположить. На рынках асимметрии и неполноты информации дивидендная политика часто используется как сигнал рыночным инвесторам о наличии средств и инвестиционных возможностях. Низкий дивидендный выход сигнализирует о наличии ограничений финансового рынка и необходимости работы на собственных внутренних источниках [Moyen, 2004]. Является ли дивидендная политика сигналом на развивающихся рынках и как велики финансовые ограничения для компаний разных отраслей, размера, структуры собственности - это предмет исследования в рамках анализа инвестиционной активности. Вторым вариантом задания проксипеременной финансовой ограниченности являются стандартные финансовые показатели кредитоспособности - коэффициенты ликвидности, долгосрочной устойчивости, Z-счет Альтмана [Chirinko, 1995; Cleary, 1999]. Исследования показывают, что имеет значение также факт наличия кредитного рейтинга [Gilchrist, 1995; Calomiris, 1995].

Еще один возможный показатель финансовой ограниченности зависимость от банковского финансирования и степень привязки к «одному поставщику капитала». Например, компании, предпочитающие банковское финансирование публичному, показывают в эмпирических исследованиях большую зависимость инвестиций от изменений в операционных денежных потоках. С другой стороны, имеет значимость теснота связи с ключевым банком [Heaton, 2001]. Чем теснее связь с банком для компании, тем менее зависимы инвестиции от текущих финансовых результатов [Hoshi, 1988]. Межстрановые сравнения также подтверждают этот вывод. Для стран с преимущественно публичным заемным капиталом в виде облигаций чувствительность инвестиций к денежным потокам выше [Bond, 1997]. При прочих равных, чем менее развиты финансовый и фондовый рынки (по величине капитализации рынков собственного и заемного капитала в отношении к ВВП, по прозрачности финансовой информации), тем более чувствительны инвестиции к внутренне генерируемым денежным средствам.

Актуальный для российского рынка вопрос - как внутренний рынок капитала при холдинговом построении с централизацией прибыли сглаживает недостаток операционных денежных потоков для инвестиционных нужд. Исследования на развитых рынках демонстрируют противоречивые результаты. Часто отмечаемый факт - взаимозависимость инвестиций по сегментам бизнеса и от денежных потоков основных бизнес-направлений (например, для нефтяных конгломератов [Lamont, 1996]). Инвестиции в сервисные и непрофильные сегменты нефтяных холдингов существенно зависимы от денежных потоков по нефтяному бизнесу, а значит, от цены на нефть, несмотря на блестящие собственные 
результаты. С другой стороны, анализ работы непромышленного сектора экономики США (медицинских клиник) показал [Calem, 1995], что инвестиции самостоятельных клиник более зависимы от волатильности денежных потоков, чем национальные сети. Насколько финансовые ограничения существенны для развивающегося российского рынка и насколько меняются инвестиционные решения при снижении операционных денежных потоков - совершенно не изученный вопрос.

В рамках третьего направления представляется перспективным исследование влияния нефундаментальных факторов на инвестиционное поведение [Baysinger, 1991]. Структура собственности (например, наличие в качестве собственника государства), сложившаяся система взаимоотношений собственников и менеджеров, включая схемы денежного вознаграждения топ-менеджеров, состав совета директоров, в ряде случаев могут оказывать существенное влияние на инвестиционный выбор. В академических исследованиях представлены работы, демонстрирующие влияние корпоративного управления (размер совета директоров, наличие независимых членов, доля акций у менеджеров, концентрация собственности, наличие блокирующего пакета) на инвестиционное поведение [Bohren,2006]. Доказывается, что компании с высоким качеством корпоративного управления больше и эффективнее инвестируют (сталкиваются с меньшими финансовыми ограничениями и имеют более высокие инвестиционные возможности).

Еще одна малоизученная область - влияние личных качеств ключевых менеджеров (степень их оптимизма, самоуверенности (например, диагностируемые по личным трансакциям менеджера в сделках с опционами и акциями), косности взглядов и т.п.)на направления инвестирования и инвестиционный бюджет [Heaton, 2002; Malmendier, 2005]. Степень такого рода влияний на принятие решений, проявления в инвестиционном поведении представляют интерес для российских собственников.

\section{Индикаторы инвестиционного поведения компаний на рынке}

Ряд показателей характеризует инвестиционное поведение компаний (таблица 1) и может выступать объясняемыми переменными в регрессионных исследованиях. В управлении компанией и для внешних аналитических исследований показатели различны, т.к. официально раскрываемая информация по инвестициям достаточно узка. Для внешних пользователей идеальной базой для исследования инвестиционного поведения мог бы стать отчет о движении денежных средств, с выделением денежных потоков за период, направляемых на модернизацию и замену внеоборотных материальных активов (CAPEX) и инвестиций в финансовые активы (LTI). Однако в раскрываемой на сайтах компаний финансовой информации и в ряде баз данных 
специализированных агентств представлены только две формы стандартной отчетности - баланс и отчет о прибылях и убытках. Из баланса может быть получена финансовая информация об изменении за период (например, год) общей величины внеоборотных активов, материальных внеоборотных активов (fixed assets), финансовых вложений (investments) и нематериальных активов (intangible assets). Привлекая информацию по амортизационным начислениям из отчета о прибыли, может быть получена оценка чистых инвестиций в материальный основной капитал - аналог САРЕХ. В эмпирических исследованиях эти показатели могут нормироваться на общую величину активов начала или конца года по балансовой или рыночной оценкам. Еще один возможный нормировочный показатель - величина выручки за год. Другие внешние и внутренние индикаторы инвестиционного поведения компании представлены в таблице.

Таблица 1

Система количественных показателей инвестиционной активности компании. Автор - Теплова Т.В. Источник: [Теплова, 2007]

\begin{tabular}{|c|c|c|}
\hline & \begin{tabular}{l}
\multicolumn{1}{c}{ Внешние } \\
индикаторы, \\
позволяющие строить \\
эмпирические \\
исследования
\end{tabular} & \begin{tabular}{l}
\multicolumn{1}{c}{ Внутренние } \\
индикаторы, которые \\
могут учитываться \\
при построении систем \\
денежного \\
вознаграждения \\
менеджеров
\end{tabular} \\
\hline \multirow{3}{*}{\begin{tabular}{l}
\multicolumn{1}{c}{ Общая } \\
инвестиционная \\
политика
\end{tabular}} & $\begin{array}{l}\text { Ежегодный темп } \\
\text { роста чистых } \\
\text { инвестиций. }\end{array}$ & \multirow{2}{*}{$\begin{array}{l}\quad \text { Веса по трем } \\
\text { портфелям } \\
\text { инвестиционных } \\
\text { стратегий: } \\
\text { высокодоходных } \\
\text { вложений (роста } \\
\text { капитала), средней } \\
\text { доходности и } \\
\text { некоммерческой } \\
\text { направленности }\end{array}$} \\
\hline & $\begin{array}{l}\text { Дивидендный выход } \\
\text { и его динамика }\end{array}$ & \\
\hline & \begin{tabular}{l}
\multicolumn{1}{c}{ Доля общей } \\
величины инвестиций в \\
основном капитале \\
компании (Inv/CE)
\end{tabular} & $\begin{array}{l}\quad \text { Структура } \\
\text { инвестиционной } \\
\text { программы по годам: } \\
\text { реальные и финансовые } \\
\text { инвестиции, на } \\
\text { замещение или создание } \\
\text { новых активов }\end{array}$ \\
\hline
\end{tabular}




\begin{tabular}{|c|c|c|}
\hline & \begin{tabular}{l}
\multicolumn{1}{c}{ Доля финансовых } \\
инвестиций (LTI) в \\
общем объеме чистых \\
инвестиций
\end{tabular} & \begin{tabular}{l}
\multicolumn{1}{l}{ Число принимаемых } \\
инвестиционных \\
проектов и их объемы в \\
динамике
\end{tabular} \\
\hline & \begin{tabular}{l}
\multicolumn{1}{c}{ Коэффициент } \\
потребности \\
инвестирования в \\
основные средства
\end{tabular} & \begin{tabular}{l}
\multicolumn{1}{c}{ Доля принятых } \\
инвестиционных \\
проектов в соответствии \\
со стратегией компании
\end{tabular} \\
\hline \multirow[t]{2}{*}{$\begin{array}{l}\text { Политика } \\
\text { замещения } \\
\text { активов }\end{array}$} & \begin{tabular}{l}
\multicolumn{1}{c}{ Степень износа } \\
материальных \\
внеоборотных активов
\end{tabular} & \multirow{2}{*}{\begin{tabular}{l}
\multicolumn{1}{c}{ Коэффициенты } \\
морального и \\
физического износа по \\
группам активов
\end{tabular}} \\
\hline & \begin{tabular}{l}
\multicolumn{2}{c}{ Коэффициент } \\
выбытия \\
фондов
\end{tabular} & \\
\hline \multirow[t]{3}{*}{$\begin{array}{l}\text { Долгосрочная } \\
\text { нацеленность/ } \\
\text { близорукость } \\
\text { инвестиций }\end{array}$} & \begin{tabular}{l}
\multicolumn{1}{c}{ Расходы на НИОКР в } \\
относительном \\
выражении (к величине \\
активов, к выручке)
\end{tabular} & \begin{tabular}{l}
\multicolumn{1}{c}{ Установленный } \\
нормативный срок \\
окупаемости вложений
\end{tabular} \\
\hline & \begin{tabular}{l}
\multicolumn{1}{l}{ Расходы на персонал } \\
(исключая заработную \\
плату и бонусные \\
выплаты) в \\
относительном \\
выражении (к величине \\
активов, к выручке)
\end{tabular} & $\begin{array}{l}\text { Ожидаемые сроки } \\
\text { жизни проектов }\end{array}$ \\
\hline & $\begin{array}{l}\quad \text { Маркетинговые } \\
\text { расходы в } \\
\text { относительном } \\
\text { выражении и в } \\
\text { сопоставлении со } \\
\text { среднеотраслевыми } \\
\text { оценками }\end{array}$ & $\begin{array}{c}\text { Средний срок жизни } \\
\text { принятых проектов }\end{array}$ \\
\hline \begin{tabular}{l}
\multicolumn{1}{l}{ Управление } \\
инвестициями в \\
оборотный \\
капитал
\end{tabular} & $\begin{array}{l}\quad \text { Коэффициент } \\
\text { потребности в } \\
\text { инвестициях в } \\
\text { оборотный капитал }\end{array}$ & \begin{tabular}{l}
\multicolumn{1}{l}{ Инвестиции по } \\
элементам оборотного \\
капитала: вложения в \\
дебиторскую \\
задолженность и запасы \\
и деинвестиции в \\
кредиторскую \\
задолженность
\end{tabular} \\
\hline $\begin{array}{l}\text { Мотивация } \\
\text { менеджеров }\end{array}$ & $\begin{array}{l}\text { Наличие бонусных } \\
\text { программ и программ } \\
\text { долгосрочного } \\
\text { вознаграждения }\end{array}$ & \begin{tabular}{l}
\multicolumn{1}{c}{ Количество } \\
инициированных \\
проектов и доля \\
принятых к реализации
\end{tabular} \\
\hline
\end{tabular}


Под чистыми инвестициями понимается величина денежного потока, направленная на инвестиционную программу текущего года, за вычетом амортизационных отчислений.

Коэффициент потребности в инвестициях в оборотный капитал рассчитывается как отношение чистого оборотного капитала (NWC) к приросту выручки, т.е. показывает, на сколько рублей следует увеличить оборотный капитал для увеличения выручки на 1 рубль.

Коэффициент потребности инвестирования в основные средства рассчитывается как отношение чистых инвестиций к приросту выручки, т.е. показывает, сколько инвестиций должно быть вложено для увеличения выручки на одну денежную единицу.

Для диагностирования относительной инвестиционной активности показатели компании сопоставляются с отраслевыми и общерыночными (страновыми) оценками.

\section{Традиционные детерминанты инвестиционного поведения в эмпирических исследованиях}

При качественном анализе инвестиционной активности компании следует учитывать влияние внешних (фундаментальных) и внутренних факторов. Обобщенным показателем влияния внешней среды может выступать инвестиционный климат, оценка которого связана с макроэкономическими и страновыми рисками, развитием финансового и фондового рынков.

Под инвестиционным климатом понимается совокупность политических, социально-экономических, финансовых, организационноправовых, природных факторов, присущих той или иной стране, региону, который определяет выбор инвесторов относительно места, времени и формы вложения денег. Инвестиционный климат складывается под влиянием не зависящих от конкретной компании процессов и существенно влияет на инвестиционное поведение. К значимым факторам, определяющим инвестиционный климат, относятся: предполагаемый темп инфляции и ставка процента на рынке, а также риски правоприменения законодательных регулирующих и налоговых норм.

О наличии благоприятного или неблагоприятного инвестиционного климата в стране часто судят по проводимой макроэкономической и монетарной политике государства. Косвенными показателями могут выступать:

1) различные рейтинги благоприятствования (например, журнал Forbes ежегодно составляет рейтинг дружелюбия стран по отношению к иностранным инвесторам, в котором учитываются такие факторы, как налоговый режим, вмешательство государства в экономику и 
регулирование цен, конкурентность рынка, ограничения для иностранцев, уровень коррупции и личные свободы $)^{5}$;

2) объемы привлекаемых на рынок прямых иностранных инвестиций (ПИИ, FDI). Этот показатель достаточно условен, т.к. ПИИ ориентируются не столько на низкие риски, сколько на соотношение рискдоходность. В ряде случаев стоимость рабочей силы (низкая в Китае) и величина рынка (Китай, Россия, Бразилия) оказываются более важными, чем риск ограничения свобод и давление государства.

Интегрирующий фактор фундаментального влияния, определяющий инвестиционные возможности компании, - предельная доходность капитала (MPK). МРК рассчитывается как отношение прироста выгод от инвестирования к приросту капитала $(\Delta \pi / \Delta \mathrm{CE})$. Часто в качестве показателя-заменителя долгосрочных инвестиционных решений выступает индикатор Q Тобина, как отношение рыночной стоимости фирмы к восстановительной стоимости капитала. В эмпирических исследованиях как объясняющая переменная используется дальнейшая корректировка MPK - сопоставление капитализации компании с балансовой оценкой, т.е. мультипликатор EV/BV или соотношение только по собственному капиталу - MV/ BVE.

Низкое значение коэффициента Q Тобина (EV/BV)сигнализирует о низких инвестиционных возможностях компании. Другим вариантом задания предельной доходности капитала (MPK) является показатель, построенный на базе выручки: MPK $=\frac{\theta \times S}{C E}$, где $\theta-$ функция от ценовой эластичности спроса на продукцию компании и вклада капитала, $\mathrm{S}-$ выручка от реализации, СЕ - вложенный капитал.

Ориентация на рыночные индикаторы компании (поведение инвесторов на рынке) при оценке инвестиционных возможностей может в ряде случаев существенно исказить инвестиционное поведение. Не всегда высокие рыночные мультипликаторы сигнализируют о потенциале роста и необходимости активизировать инвестиционную деятельность. Безусловно, фондовый рынок влияет на инвестиции компании, изменяя стоимость заемных и собственных средств и соответственно ставку отсечения по рассматриваемым проектам. Когда инвестиционная политика не делегируется менеджерам, которые могут иметь больше информации о потенциале развития компании, собственники в ряде случаев принимают решения, базируясь исключительно на оценках фондового рынка. Как результат - возможны поведенческие искажения рационального выбора и возникновение так называемых

\footnotetext{
5 За 2005 год первые места в инвестиционной привлекательности заняли Дания, Финляндия, Исландия, США, Британия, Сингапур, Австралия, Эстония, Люксембург, Латвия, Нидерланды, Мальта, Литва. Казахстан - на 98 месте, Китай — на 102, Россия — на 103, Украина - на 107, Белоруссия - на 130.
} 
«инвестиционных пузырей». Однако эмпирические исследования не подтверждают наличие пузырей в реальных инвестициях.

В работе Чиринко [Chirinko, 1996] авторы впервые исследуют зависимость между инвестиционным поведением американских фирм и существованием на фондовом рынке пузырей, не обусловленных фундаментальной стоимостью активов, и приходят к выводу, что реальные инвестиции не зависят от пузырей и основываются на фундаментальных показателях. Развитие этой идеи представлено в работе Гилхрист [Gilchrist, 2005], где авторы проверяют следующую гипотезу: фирмы используют наличие пузырей на рынке, выпуская новые акции по завышенным ценам, что уменьшает затраты на капитал и увеличивает реальные инвестиции. Следовательно, мы вправе ожидать, что реальные инвестиции растут в периоды переинвестирования на фондовом рынке. Результаты исследования эту гипотезу не подтверждают. Наоборот, показано, что реальные инвестиции находятся в обратной зависимости от пузырей на фондовом рынке, вызванных разбросом мнений инвесторов по поводу будущей цены акции.

В 90-е годы на развитых рынках проведен ряд исследований зависимости доходности акций и инвестиционной активности компаний. Однозначный вывод не получен и можно говорить о трех гипотезах влияния.

1. Фондовый рынок - пассивный предсказатель перспектив компании, так как цены акций отражают уже осуществленные проекты. Как результат - менеджеры и собственники в принятии инвестиционных проектов не ориентируются на оценки фондового рынка. Зависимость инвестиционной активности (через показатель доли инвестиций в общем капитале) от рыночных мультипликаторов отсутствует.

2. Собственники рассматривают фондовый рынок как источник информации о будущем компании, однако существует понимание возможных ошибок рыночных инвесторов (особенно в ситуации асимметрии информации и нерациональности поведения). Инвестиционная активность в этом случае слабо связана с рыночной динамикой цен акций компании [Barro, 1990], однако значительные сигналы (сильный рост цен на акции) могут стимулировать инвестиционную активность.

3. Рыночная цена акций оказывает непосредственное влияние на инвестиции. Снижение цены акции заставляет менеджера отложить инвестиции, т.к. свидетельствует о негативном восприятии доступных для компании инвестиционных проектов. Скорее всего, менеджер, опасаясь дальнейшего падения цены и увеличения вероятности поглощения компании, сохранит избыточные денежные средства для проведения защитных тактик. Рост капитализации компании демонстрирует менеджеру, что рынок оценивает перспективы компании как благоприятные и стимулирует инвестиционную активность. 
Анализ влияния неопределенности на инвестиционную активность, как второго по значимости фундаментального объясняющего фактора, имеет ряд проблемных вопросов. Первая проблема заключается в трактовке (измерении) неопределенности. В общем случае под неопределенностью (как синоним часто используется термин «риск») понимается возникновение таких ситуаций, которые порождаются изменением внешней среды или неуправляемыми внутренними процессами и приводят к отклонениям финансовых и нефинансовых метрик функционирования компании от ожидаемых значений. Среди финансовых показателей традиционно рассматриваются отклонения в величинах рыночной стоимости, прибыли, денежного потока, балансовой оценки отдельных элементов активов и пассивов.

В общем случае неопределенность отражает ожидания менеджеров и собственников компаний относительно будущих событий. Следовательно, этот показатель нельзя наблюдать и фиксировать (ex post), он отражает прогнозы и ожидания (ex ante). На практике оценка неопределенности в эмпирических исследованиях вводится по наблюдаемым в прошлом отклонениям. Р. Пиндайк [Pindyck, 1991)] показал, что увеличение волатильности на товарном рынке оказывает прямое влияние на волатильность рынка акций. В работе Берка [Berk, 1999] показано, что изменение во времени доходности акций связано с ожиданиями относительно доходности активов, имеющихся в распоряжении компании и потенциальными возможностями роста. Если рынок эффективен, то новости относительно фундаментальных факторов использования активов и будущих возможностей компании отражены в наблюдаемых ценах. Отсюда делается вывод, что волатильность цен и доходности акций отражает ожидания изменений в деятельности компаний и является адекватной мерой общего риска, который учитывается при принятии инвестиционных решений.

В академической литературе предложены различные подходы к выявлению факторов неопределенности. Обычно выделяют четыре группы факторов, формирующих для компании ситуацию неопределенности (волатильности финансовых результатов, например, денежных потоков по собственному капиталу - CFE): рыночные, отраслевые и внутрифирменные (специфические). Рыночные факторы неопределенности связаны с движением рыночных цен (цены на финансовые и реальные активы, обменный курс, процентные ставки). Второй вид неопределенности (отраслевой риск), прежде всего связан с изменениями в спросе и предложении на продукцию компании из-за поведения конкурентов. К отраслевому риску часто относят и факторы, определяющие поведение поставщиков и покупателей продукции. Третий вид неопределенности вызван рассогласованием внутренних процессов (операций, используемых технологий) с внешними событиями, т.е. порождается неадекватностью использования внутренних бизнес- 
процессов и носит название специфического риска компании. К этому виду риска могут быть отнесены и факторы отклонений, проистекающие из-за сложных взаимоотношений между заинтересованными в функционировании компании лицами, так называемые «риски агентских отношений». Четвертый вид неопределенности связан с взаимоотношениями компании и кредиторов - кредитный риск. Погашение долгов может совпасть с периодом снижения в поступлении денег и породить технический или реальный дефолт.

В таблице 2 сгруппированы некоторые из факторов, формирующих неопределенность в рамках выделенных групп, а также приведены ссылки на исследования, посвященные анализу влияния этих факторов на инвестиционные решения компании.

Таблица 2

Исследования влияния факторов неопределенности на инвестиционную активность \{Bulan, 2005; Теплова, 2007\}

\begin{tabular}{|c|c|}
\hline $\begin{array}{l}\text { Эмпирические } \\
\text { исследования }\end{array}$ & Вводимый фактор неопределенности \\
\hline \multicolumn{2}{|c|}{ Общзая (рыночная) неопределенность } \\
\hline $\begin{array}{l}\text { [Pindyck, } 1991] \\
\text { [Goel,2001] }\end{array}$ & Инфляция \\
\hline [Pennings, 2000] & Налоги \\
\hline $\begin{array}{l}{[\underline{\text { Ferderer}}, 1993]} \\
{[\underline{\text { Bo }}, 2002]} \\
{[\text { Kogan, 2004] }}\end{array}$ & $\begin{array}{l}\text { Волатильность акций относительно рынка } \\
\text { (фондового индекса) }\end{array}$ \\
\hline \multicolumn{2}{|c|}{ Неопределенность на уровне отрасли } \\
\hline $\begin{array}{l}{[\underline{\text { Hartman }}, 1972]} \\
{[\underline{\text { Abel }}, 1983]} \\
{[\underline{\text { Hurn }}, 1994]} \\
{[\underline{\text { Abel }}, 1997]} \\
{[\underline{\text { Fuss }}, 2004]}\end{array}$ & $\begin{array}{l}\text { Ценовые шоки (будущие колебания цен на } \\
\begin{array}{l}\text { выпускаемый продукт, выявляемые по } \\
\text { анализу дисперсии цен в прошлом) }\end{array}\end{array}$ \\
\hline $\begin{array}{l}\text { [Caballero, } 1991] \\
\text { [Sterken, 2002] }\end{array}$ & $\begin{array}{l}\text { Шоки спроса (изменение спроса на } \\
\text { выпускаемый продукт) }\end{array}$ \\
\hline $\begin{array}{l}\text { [Abel, 1994] } \\
{[\underline{\text { Ghosal }}, 2000]}\end{array}$ & $\begin{array}{l}\text { Отклонения прибыли на отраслевом уровне } \\
\text { от прогнозных оценок (анализ остатков } \\
\text { регрессионного уравнения) }\end{array}$ \\
\hline \multicolumn{2}{|c|}{ Специифическая неопределенность (на уровне компании) } \\
\hline $\begin{array}{l}{[\underline{\text { Bulan, }}, 2005]} \\
{[\underline{\text { Shaanan, }}, 2005]}\end{array}$ & $\begin{array}{l}\text { Дисперсия доходности } \\
\text { объясненная волатильностью рыночй } \\
\text { отраслевых индексов }\end{array}$ \\
\hline $\begin{array}{l}{[\underline{\text { Leahy, 1996] }}} \\
{[\underline{\text { Bloom }}, 2003]}\end{array}$ & $\begin{array}{l}\text { Дисперсия ежедневной (месячной или } \\
\text { еженедельной) доходности } \\
\text { (прогнозные или наблюдаемые значения) }\end{array}$ \\
\hline [Bond, 2004] & Расхождение мнений аналитиков по поводу \\
\hline
\end{tabular}




\begin{tabular}{|l|l|}
\hline & $\begin{array}{l}\text { будущей прибыли (EPS компании) как } \\
\text { отклонение прогнозов на данный год, а } \\
\text { также дисперсия ошибки прогнозов за } \\
\text { предыдущие 2 года. }\end{array}$ \\
\hline
\end{tabular}

Интересным вариантом задания объясняющей переменной, характеризующей неопределенность, является разброс мнений аналитиков. Так, в работе Бонда с соавторами [Bond, 2004] в качестве меры неопределенности выбрано расхождение мнений аналитиков по поводу будущей прибыли компании (EPS, earnings per share). Базовой мерой неопределенности выбрана величина отклонений прогнозов на данный год. В качестве второй возможной меры рассмотрена дисперсия ошибки прогнозов за предыдущие 2 года. Заметим, что данная модель анализа применима, когда на рынке действуют в течение нескольких лет аналитические компании, предоставляющие прогнозы финансовых показателей, причем исторические данные как по прогнозам, так и по фактическим финансовым показателям доступны.

Традиционная инвестиционная аналитика исходит из того, что только рыночный риск определяет инвестиционные решения компании (чем выше рыночный риск, тем больше значение бета-коэффициента У. Шарпа и тем выше требуемая доходность по инвестированию, которая выступает в качестве барьерной ставки инвестиционного проекта).

Результаты, полученные в эмпирических исследованиях на базе традиционных метрик риска по степени значимости систематического риска, не демонстрируют неожиданных результатов. Например, Дж. Фердерер [Ferderer, 1993] исследует, как неопределенность, в качестве меры которой используется премия за риск, оцениваемая на основании информации фондового рынка, влияет на инвестиции развитого рынка США. Два вывода, которые получает Дж. Фердерер, таковы:

1. Увеличение систематического риска отрицательно влияет на инвестиции фирм в основной капитал.

2. Неопределенность оказывает большее влияние на инвестиции, чем стоимость капитала (затраты на капитал) или среднее значение Q Тобина.

Фиксация неопределенности по другим метрикам дает неоднозначные результаты. В работе Харна [붕, 1994] представлены результаты исследования компаний, занимающихся добычей нефти в Северном море. Анализ показал слабую зависимость инвестиций этих фирм от изменения цен на нефть. Авторы отмечают, что ожидаемая цена на нефть влияет на временную задержку фирмы при принятии необратимого инвестиционного решения, однако сама волатильность цены, используемая в качестве меры неопределенности, влияния на инвестиции в регрессионном анализе не имеет.

Работа Хозала [Ghosal, 1996], в которой исследуется влияние волатильности товарных цен на инвестиции на панельных данных по 
отраслям промышленности США, также показывает неоднозначный вывод. С одной стороны, при исследовании совокупных инвестиций авторы, как [ㅂorn, 1994], приходят к выводу о том, что это влияние незначимо. С другой стороны, при анализе отдельных отраслей обнаруживается значимая отрицательная зависимость инвестиций от неопределенности в отраслях с низкой концентрацией фирм, т.е. в отраслях, которые можно считать близкими к конкурентным. В отраслях же с высокой концентрацией зависимость оказалась незначимой.

Неоднозначность выводов связана с игнорированием в инвестиционных решениях такого важного свойства, как управленческая гибкость. Эта характеристика компании и менеджмента позволяет скорректировать как стратегию компании, таки траекторию реализации отдельного инвестиционного проекта при изменении тех или иных внешних параметров среды. Управленческая гибкость с 80-х годов XX века анализируется в терминах реальных опционов (опционной терминологии, введенной С. Майерсом). Наличие опциона на отсрочку инвестирования (особенно для проектов с необратимыми инвестициями, где могут быть выстроены барьеры на вход конкурентам) позволяет компаниям более гибко подстраиваться к негативным факторам внешней среды. Право отсрочки инвестиционного решения имеет ценность в двух случаях, когда: 1) инвестиции необратимы, и 2) высока неопределенность будущего положения. Можно предположить, что необратимость инвестиций компании тесно связана с отраслевой принадлежностью. Концепция реальных опционов, в отличие от портфельной (например, модели САРМ с акцентом на рыночный риск) исходит из того, что весь риск компании или все факторы неопределенности, а не только систематический риск, определяют инвестиционный выбор. Для нашего исследования важной представляется проверка гипотезы о влиянии специфического риска.

Таким образом, вторая проблема выявления роли неопределенности в инвестиционном поведении связана с необходимостью рассмотрения влияния в двух аспектах. Во-первых, в условиях неопределенности инвестиционная активность (объем инвестирования) падает из-за прямой зависимости от рыночного риска, как прогнозирует классическая теория финансов и подтверждают эмпирические исследования на развитых рынках. Во-вторых, компании обладают правом (опционом) на инвестирование. Решение инвестировать дополнительную единицу капитала может быть представлено как реальный опцион [Pindyck, 1988]. Для выявления оптимального уровня инвестиционной активности (которая максимизирует стоимость компании) необходимо оценивать не только собственно инвестиционное решение, но и права на него (с учетом возможности удержания права). C ростом неопределенности ценность опциона на инвестиции (стоимость права, возможности будущих инвестиций) возрастает. Более того, при 
сохранении опциона стоимость компании максимизируется. Парадокс, но такая ситуация соответствует низкой величине оптимального инвестиционного бюджета (в ситуации высокой нестабильности и барьеров на вход). Следовательно, рост неопределенности должен вызывать снижение оптимальной величины инвестиций компании, которая обладает правом (возможностью) отложить инвестиционные решения.

Рассматривая факторы неопределенности через волатильность цен акций и проводя декомпозицию наблюдаемой доходности акций компании по факторам рыночного, отраслевого и специфического риска (через введение трех бета-коэффициентов, отражающих чувствительность компании к рынку и отрасли), можно оценить степень влияния рыночной и отраслевой волатильности на инвестиционное поведение. Эмпирическое исследование по выборке из 2900 американских производственны компаний, проведенное Л. Булан [Bulan, 2005] на отрезке с 1964-го по 1999 год, позволило подтвердить гипотезу о том, что периоды высокой отраслевой и операционной нестабильности соответствуют низким показателям инвестирования (оцениваемым через рассчитанный по компаниям коэффициент «инвестиции за год /капитал на начало года», Inv/CE). Более того, влияние опционной (гибкой) политики отсрочки инвестирования превалирует в выборе инвестиционного бюджета над традиционной реакцией снижения инвестиций под влиянием рыночных факторов. Так, увеличение на одно стандартное отклонение отраслевого риска сокращает коэффициент Inv/CE на $6,4 \%$, а увеличение на одно стандартное отклонение специфического риска компании более существенно снижает инвестиционную активность - на 19,3\%. С другой стороны, увеличение волатильности Q Тобина на одно стандартное отклонение приводит к росту коэффициента инвестирования только на 5\%. Автор делает вывод, что отраслевая и специфическая неопределенность являются основными детерминантами инвестиционных решений американских компаний при специфичности активов в отрасли (большой доли необратимых инвестиций).

В других эмпирических исследованиях также отмечаются отраслевые различия в реакции инвестиций компаний на неопределенность. Так, Гоэл и Рэйм [Goel и Ram,2001] по данным восьми стран (Франция, Германия, Бельгия, Япония, США, Великобритания, Канада, Дания) за период 1981-1992 годов проанализировали чувствительность инвестиций в наукоемкие секторы экономики с высокими затратами в НИОКР (R\&D), где инвестиции в большей степени необратимы и другими направлениями деятельности (non-R\&D). Полученные выводы таковы:

1) инвестиции в сектора c высокими $R \& D$ затратами более чувствительны к темпам инфляции и к изменениям темпов инфляции (эти 
два фактора определяют цены на входе и на выходе для фирмы и в модели являются факторами неопределенности);

2) объем инвестиций(точнее, отношение $\mathrm{Inv}_{\mathrm{i}} / \mathrm{GDP}_{\mathrm{i}}$ ) отрицательно зависит от инфляции и ставки процента. Напротив, для сектора non-R\&D неопределенность, рассматриваемая как инфляционные ожидания, незначимый фактор.

Таким образом, фактор необратимости инвестиций (как специфическая отраслевая черта, отражающая невозможность выхода из инвестиционного решения из-за уникальности активов и низкой ликвидационной стоимости) должен рассматриваться как существенный при рассмотрении степени влияния факторов неопределенности на инвестиционную активность. В США существует классификация отраслей по уровню необратимости на базе рассчитываемого индекса необратимости (Irreversibility Index). Эти отраслевые поправки следует вводить в анализ.

Эмпирическое исследование факторов, влияющих на инвестиционную активность по крупнейшим российским компаниям

Задача, поставленная в качестве первого этапа исследования инвестиционной активности российских компаний регрессионным методом, - провести тестирование традиционно рассматриваемых факторов, определяющих инвестиционное поведение, на базе информации по российскому рынку. В качестве объекта анализа построена выборка из 28 крупных российских компаний, по которой собрана рыночная и отчетная финансовая информация за последние 5 лет. В регрессионное уравнение включены финансовые показатели деятельности, характеризующие достаточность денежных средств для инвестирования: рентабельность продаж (маржа прибыли), доходность уже осуществленных инвестиций (ROI, ROCE), операционные денежные потоки в относительном выражении), а также рыночный показатель инвестиционных возможностей (возможностей роста) как отношение капитализации компании к ее балансовой стоимости.

В качестве факторов неопределенности введены показатели рыночного (чувствительность доходности акций компании к рыночному индексу) и специфического риска (не объясненная рынком волатильность цен акций). Как объясняемая переменная рассмотрены два параметра инвестиционной активности: реальные инвестиции (измеряемые по данным баланса и отчета о движении денежных средств (CAPEX)) и долгосрочные финансовые вложения (LTI), измеряемые по балансовым данным.

\section{Гипотеза и регрессионная модель}


Проверяемая гипотеза: чем выше коэффициент инвестиционных возможностей $(\mathrm{MV} / \mathrm{BV})$, доходность инвестиций и рентабельность, фиксируемые на конец года, тем выше инвестиционные расходы компании в следующем году. Рост рыночного и специфического рисков приводит к снижению инвестиционной активности.

Построенная для оценки гипотезы модель в общем виде имеет вид:

$$
\text { (1) }\left(\frac{\operatorname{Inv}}{C E}\right)_{i, t}=\alpha_{0}+\alpha_{1}\left(\frac{M}{B}\right)_{i, t-1}+\alpha_{2}\left(\frac{C F}{C E}\right)_{i, t-1}+\alpha_{3} R O I_{i, t-1}+\alpha_{4} \hat{\beta}_{i, t} \hat{\sigma}_{M t}+\alpha_{5} \hat{\sigma}_{\varepsilon, i, t}
$$

Зависимая переменная в модели - относительная величина инвестиций компании (Inv). CE - оценка капитала, которая в данном исследовании фиксируется по балансовой стоимости. Значение $C E$ рассчитывается как суммарные активы компании (валюта баланса) за вычетом краткосрочных обязательств. Предполагается, что инвестиционные решения принимаются в начале t-го года. Инвестиции периода $\mathrm{t}$ в модели для общего случая рассчитываются по балансовым данным как

Inv $t=$ Валюта баланса $t-$ Текущие активы $t-($ Валюта баланса $t-$ 1 - Текущие активы $t$ - 1),

то есть как изменение внеоборотных активов. При этом выбытие и продажа активов, а также их переоценка отдельно не учитываются в модели, так как по данным баланса можно отследить только общее изменение внеоборотных активов. Инвестиции как изменение балансовой строки «Long-Term Investment» - показатель инвестиций в долгосрочные финансовые активы (долгосрочные финансовые вложения).

Коэффициент M/B (market-to-book ratio, Q Тобина) определяется делением рыночной капитализации компании на балансовую стоимость собственного капитала. Балансовая стоимость собственного капитала компании определяется как разность между суммарными (совокупными) активами и обязательствами компании.

Выдвинутая в модели гипотеза исходит из того, что если рыночный мультипликатор $\mathrm{M} / \mathrm{B}>1$, то у компании имеются возможности роста, инвесторы благосклонно оценивают ее перспективы. Если коэффициент M/В < 1, то это свидетельствует о недооценке рынком компании, ограниченности ее возможностей роста.

Показатель ROI (отдача от инвестиций) рассчитывался в двух вариантах: 1) на безналоговой основе, как отношение операционной прибыли (EBIT) к вложенному капиталу (CE); 2) по чистой прибыли. Если предположить, что менеджмент не может влиять на величину уплачиваемого налога на прибыль, то более информационным должен быть первый вариант. Показатель ROI должен отразить качество принимаемых решений менеджментом. В качестве заменителя операционного денежного потока (CF) в модели рассматривалась операционная прибыль, суммированная с амортизационными начислениями. Показатели M/B, ROI и CF рассчитывались для года $\mathrm{t}$ - 1 , 
то есть прошлого по отношению к инвестиционному решению (года $\mathrm{t}$ ). Рентабельность продаж рассчитывалась как отношение прибыли к выручке, например, как EBIT/ Sales.

Меры риска (неопределенности), включаемые в модель, отражают рыночный $\left(\hat{\beta}_{i, t} \hat{\sigma}_{M t}\right)$ и специфический $\left(\hat{\sigma}_{\varepsilon, i, t}\right)$ риски для t-го года. Для исключения влияния дополнительного финансового риска на волатильность акций компании (дисперсия цены акции отражает общий риск, включая финансовый) была сделана следующая корректировка:

$$
\sigma_{i}^{\prime}=\frac{\sigma_{i}}{D / E} .
$$

Также в регрессию была введена дамми-переменная, характеризующая структуру капитала компании. Если больше $50 \%$ акций компании принадлежат государству, дамми-переменной присваивается значение 1 , в остальных случаях - 0 .

\section{Панель исследования}

Так как внимание акцентировалось на влиянии внешних (рыночных) факторов, то к отбору компаний предъявлялись следующие требования: длительная торговая история на фондовых биржах РФ (минимум 4 года),ликвидность акций, однородность компаний по размеру, так как часть финансовых ограничений проистекает из-за малого размера. На базе сопоставления бирж ММВБ и РТС по ликвидности, в качестве базы данных о рыночной динамике выбрана торговая площадка ММВБ. Отбор ликвидных акций проводился по уровню капитализации. С сайта www.quote.ru отобраны компании с высокой (больше 1 млрд долл.) капитализацией. Вторым фактором отбора выступал объем деятельности (годовая выручка больше 10 млн долл). Из отобранных компаний исключены те, акции которых котируются на рынке меньше 5 лет. Итоговая выборка составила 28 компаний нефинансового сектора экономики. Период наблюдения - с 2000-го по 2005 год. Итого 146 наблюдений. В выборку вошли «Газпром», НК «Лукойл», «Сургутнефтегаз», «Газпромнефть» («Сибнефть»), «Вымпелком», «Норильский Никель ГМК», «Самараэнерго», «Балтика»,РАО ЕЭС РФ, «Татнефть», «Мегионнефтегаз», НК «Пурнефтегаз», «Удмуртнефть», «Ростелеком», «Волгателеком», МТС, «Мосэнерго», «АвтоВАЗ», МГТС, «Уралсвязьинформ», «Сибирьтелеком», «Северо-Западный Телеком», РБК-ИС.

Источником данных по ежедневной, еженедельной и ежемесячной цене акции и объему торгов являлся интернет-ресурс www.finam.ru. Это одна из самых уважаемых в России информационных онлайн-систем, содержащая информацию о котировках акций и индексов в удобном для 
извлечения формате. В качестве рыночного индекса для определения рыночного и специфического рисков компаний был взят индекс РТС, так как на него ориентируются международные информационные агентства (например, S\&P, Bloomberg). Все показатели стандартной финансовой отчетности компаний взяты из баз данных Bloomberg и Factiva. Стоит отметить, что система Bloomberg имеет более полную базу данных по отчетности российских публичных компаний. Но в системе Factiva есть отчеты по компаниям, подготовленные банками и аналитическими агентствами, ссылки на официальные сайты компаний. Эта система, в первую очередь новостная, создана компанией Reiters и удобна в обращении.

\section{Результаты исследования}

В целом регрессионное исследование подтвердило предложенную гипотезу. Выявлена положительная зависимость инвестиционных расходов российских компаний от рентабельности продажи доходности осуществленных ранее инвестиций, и отрицательная зависимость от факторов риска. Важный результат - направления инвестирования детерминированы различными факторами. В принятии решений по капитальным вложениям российские компании в первую очередь ориентируются на рыночные оценки перспектив роста (Q Тобина) и на отдачу на вкладываемый капитал (ROI), оцениваемую либо по операционной прибыли, либо по операционному денежному потоку. Из рыночного и специфического риска большее влияние принадлежит специфическому риску, что хорошо объясняется наличием опциона на отсрочку инвестирования. Финансовые инвестиции имеют иные детерминанты.

Более подробно результаты могут быть охарактеризованы следующим образом:

\section{1. Тестирование детерминант зависимой переменной «Инвестиции», вводимой по изменению величины внеоборотного капитала по балансу}

Выбор измерителя неопределенности по волатильности доходности (недельная, дневная или месячная) не влияет на итоговый результат, факторы специфического риска незначимы, зависимость от рыночного рынка положительна, что противоречит результатам исследований на развитых рынках. Данная положительная зависимость (чем больше риск, тем больше инвестиции) косвенно согласуется с основными предположениями теории реальных опционов.

Зависимость от доходности капитала и рентабельности продаж, а значит, и от заработанных компанией денежных потоков, положительна. 
Выбор показателя прибыли (до налогообложения, операционная или чистая) незначительно влияет на результаты. Тем не менее прибыль до налогообложения - наиболее подходящий показатель прибыли для

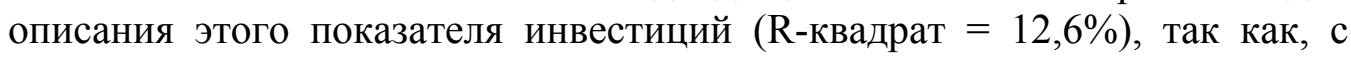
одной стороны, отражает деятельность компании в целом (не только основной вид деятельности, как операционная прибыль), лучше характеризует качество управления и, в отличие от посленалоговой прибыли, очищена от эффектов, связанных с налоговой оптимизацией. Наличие государства в качестве собственника положительно влияет на инвестиционную активность. Переменная, отражающая роль государствасобственника, значима. Компании с высокой долей государственного участия инвестируют больше.

\begin{tabular}{lcccc}
\hline \multicolumn{1}{c|}{ Месяч } & Коэффициентьл & Ст. ошибка & P-valuе \\
\hline Пересечение & $-0,531174608$ & 0,142327703 & 0.000274647 \\
PreTaxProfit/Capital stock & 0,372992757 & 0,125196363 & 0.003403404 \\
PreTaxProfit/Sales & 0,627742763 & 0,256503856 & 0.015622349 \\
Market risk based on monthly returns & 1,443447451 & 0,520118397 & 0.006264937 \\
Dummy (government share) & 0,2576821 & 0,115349916 & 0.027062913 \\
& & & \\
\hline Кол-во наблюдений & 146 & & \\
R2-adjusted & 0,10 & & \\
F-стастистика & 5.08655707 & & \\
\hline
\end{tabular}

\section{2. Тестирование детерминант зависимой переменной} «Реальные инвестиции», вводимой по изменению величины реальных активов(Net Fixed Assets)

Регрессионное построение показало, что для данного показателя инвестиций значимы накопленные денежные средства на балансе в конце года (зависимость положительная), специфический риск компании (зависимость отрицательная), который по значимости превалирует над рыночным риском, что подтверждает гипотезу о важности учета опционных возможностей. Значим также показатель $Q$ Тобина: зависимость отрицательная, что, возможно, объясняется тем, что в модели берется М/B ratio предыдущего по отношению инвестициям периода, то есть инвестиции в реальные активы совершаются тогда, когда менеджмент компании замечает, что компания недооценена на рынке. Следует отметить, что это направление инвестирования компании плохо поддается описанию через классические финансовые показатели. Объясняется только 6-7\%изменений. Как общий результат исследования, отрицательная зависимость реальных инвестиций от рыночного и специфического риска согласуется с результатами зарубежных исследований. 


\begin{tabular}{l|c|c|c|}
\hline \multicolumn{1}{|c|}{ Месяи } & Коэффичиенты & Ст. ошибка & P-valuе \\
\hline Пересечение & 0,12147665 & 0,056736435 & 0,033986423 \\
PreTaxProfit/Capital stock & 0,12787943 & 0,066934545 & 0,058096322 \\
PreTaxProfit/Sales & 0,33128724 & 0,132294323 & 0,013413232 \\
M/B & $-0,04408434$ & 0,022128543 & 0,048277312 \\
Specific risk based on monthly & & & \\
returns & $-0,4855112$ & 0.17675912 & 0,00680532 \\
& & & \\
\hline кол-во наблюдений & 146,00 & & \\
R2-аdjusted & 0,07 & & \\
F-стастистика & 3.789177 & & \\
\hline
\end{tabular}

\section{3. Тестирование детерминант зависимой переменной} «Реальные инвестиции», вводимой по величине САРЕХ из отчета о движении денежных средств

При выборе показателя CAPEX (Capital expenditures) как показателя реальных инвестиций зависимость от финансовых факторов проявляется наиболее сильно, изменения объясняются на $33 \%$. Капиталовложения положительно зависят от показателя отдачи на капитал и коэффициента Q Тобина, отрицательно - от специфического риска.

\begin{tabular}{l|c|c|c|}
\hline \multicolumn{1}{|c|}{ Месяц } & Коэффичиентьл & Ст. ошибка & P-valuе \\
\hline Пересечение & 0,126948289 & 0,022608832 & $1,47 \mathrm{E}-07$ \\
EBIT/Capital stock & 0,104395838 & 0,032612609 & 0,001785928 \\
EBIT/Sales & 0,161257771 & 0,075245009 & 0,034288657 \\
M/B & 0,011880536 & 0,00562799 & 0,03701959 \\
Рыночный риск & $-0,17754881$ & 0,082947287 & 0,03450304 \\
Специфический риск & $-0,147665364$ & 0,036893296 & 0,00011349 \\
& & & \\
\hline кол-во наблюдений & 117 & & \\
R2-аdјusted & 0,38 & & \\
F-стастистика & 15.26648912 & & \\
\hline
\end{tabular}

Из всех показателей прибыли наиболее точно описывает изменения этого вида инвестиций операционная прибыль.

\section{4. Тестирование детерминант зависимой переменной «Финансовые инвестиции», вводимой по изменению показателей LTI в балансе}

Финансовые инвестиции компаний слабо объясняются прошлыми финансовыми показателями на основе чистой прибыли и доналоговой прибыли (порядка $6 \%$ изменений описываются выделенными классическими переменными). Если для расчета показателей риска брать 
дневные доходности акций, то уравнение регрессии выглядит следующим образом:

\begin{tabular}{lcccc}
\hline \multicolumn{1}{c|}{ Месяц } & Коэффициенть & Ст. ошибка & P-value \\
\hline Пересечение & $-0,291349735$ & $-3,303538153$ & 0,001302561 \\
M/B & 0,035661593 & 1,876720622 & 0,063306509 \\
Рыночный риск & 0,455171271 & 1,887196916 & 0,061869439 \\
Специфический риск & 0,325126253 & 2,234924511 & 0,027519884 \\
$\begin{array}{l}\text { Дамми-переменная (Dummy, } \\
\text { government share) }\end{array}$ & 0,097456091 & 2,006113952 & 0,047391209 \\
& & & \\
кол-во наблюдений & 111 & \\
R2-аdјusted & 0,06 & \\
F-стастистика & 2.700374161 & & \\
\hline
\end{tabular}

Однако если показатели доходности на капитал и рентабельности продаж брать на основе операционной прибыли, то объяснительная способность растет и, в противоречии с первоначальной гипотезой, зависимость от рентабельности отрицательная, а зависимость от рыночного риска - положительна.

\begin{tabular}{lcccc|}
\hline \multicolumn{1}{|c|}{ Месяц } & Коэффициенты & Ст. очибка & P-value \\
\hline Пересечение & $-0,024642959$ & 0,049894344 & 0,622387149 \\
EBIT/Capital stock & 0,273460972 & 0,097599586 & 0,006032028 \\
EBIT/Sales & $-0,765037018$ & 0,20367012 & 0,000281071 \\
Market risk based on daily returns & 0,613131579 & 0,237890985 & 0,011316893 \\
& & & \\
\hline кол-во наблюдений & 111,00 & \\
R2-adjusted & 0,11 & \\
F-стастистика & 5,42 & \\
\hline
\end{tabular}

Полученный вывод можно объяснить выбором компаниями стратегии диверсификации. Если по предыдущему году рентабельность по операционной прибыли (EBIT) была низкой, то есть от основной деятельности компания не смогла получить хороший финансовый результат, то инвестиционное решение принимается в области покупки долей (контроля) в других компаниях, чтобы максимизировать прибыль на этом сегменте.

\section{Общий вывод по исследованию}

Факторы неопределенности, а также финансовые результаты деятельности компании оказывают различное влияние на реальные и финансовые инвестиции. Гипотеза о влиянии на инвестиционное 
поведение мнения фондового рынка о потенциальных возможностях роста не может быть отвергнута. Для финансовых инвестиций основным объясняющим фактором является неопределенность (введенная по специфическому и рыночному риску). При этом рыночный риск оказывает большее влияние на инвестиционное поведение, чем специфический, что связано с обратимостью данного вида вложений и косвенно доказывает гипотезу о наличии влияния специфических факторов риска для необратимых инвестиций. Детерминантами реальных инвестиций являются наличие собственных денежных средств (высокие значения накопленного денежного потока, рентабельность), инвестиционные возможности, диагностируемые фондовым рынком, и специфический риск.

\section{Список литературы}

1. Abel A., Dixit A., Eberly J., Pindyck R. Options, the value of capital and investment //The quarterly Journal of economics, Vol 111, № 3, Aug., 1996.

2. Abel A.B., Eberly, J.C. An exact solution for the investment and market value of a Firm facing uncertainty, adjustment costs, and irreversibility// Journal of Economic Dynamics and Control, V. 21, 1997.

3. Abel A.B., Eberly J.C. A Unified Model of Investment Under Uncertainty // American Economic Review, Vol. 84 . № 1, 1994.

4. Audretsch David B., Julie Ann Elston. Does firm size matter? Evidence on the impact liquidity constraints on firm investment behavior in Germany //International Journal of Industrial Organization, № 20, 2002.

5. Barro Robert J. The Stock Market and Investment //Review of Financial Studies, 3, 1990.

6. Baysinger Barry D., Rita D. Kosnik; Thomas A. Turk. Effects of Board and Ownership Structure on Corporate R\&D Strategy//The Academy of Management Journal, V. 34, № 1. , Mar., 1991.

7. Berk J.B., Green R.C., V. Nayk. Optimal investment, growth options and security returns //Journal of Finance, V. 54, 1999.

8. Bigsten P., Collier S. Derconand others. Investment in Africa's manufacturing sector: a four country panel data analysis //Oxford bulletin of economics and statistics, 61, 4, 1999.

9. Bloom Nicholas, Bond Stephen Roy, Van Reenen John.Uncertainty and Company Investment Dynamics: Empirical Evidence for UK Firms// CEPR, Discussion Papers,4025, 2003.

10. Bo Hong, Zhihai Zhang. The impact of uncertainty on firm investment: evidence from machinery industry in Liaoning province of China//Economic Systems 26, 2002. 
11. Bohren Oyvind, Ilan Cooper and Richard Priestley. Corporate Governance and Real Investment Decisions // Working paper, BI Norwegian School of Management, March 1, 2006.

12. Bond Stephen,Michael Devereux, Fabio Schiantarelli, Richard Blundell. Investment and Tobin's Q: Evidence from company panel data //Journal of Econometrics, № 51, 1992.

13. Bond Stephen, Julie Elston, Jacques Mairesse, Benoit Mulkay. Financial factors and investment in Belgium, France, Germany and the UK: a comparison using company panel data /NBER, Working paper, 1997.

14. Bulan Laarni T. Real options, irreversible investment and firm uncertainty: New evidence from U.S. firms//Review of Financial Economics, № 14, 2005.

15. Caballero R. On the sign of the investment-uncertainty relationship//The American Economic Review, Vol. 81, Mar., 1991.

16. Calem P., J. Rizzo. Financing Constraints and Investment: New Evidence from Hospital Industry Data // Journal of Money, Credit and Banking. № 27, 1995.

17. Calomiris C., C. Himmelberg, P. Wachtel. Commercial paper and Corporate finance: a microeconomic perspective //Carnegie-Rochester conference series on Public Policy, 1995.

18. Chirinko Robert S., Huntley Schaller. Bubbles, fundamentals, and investment:A multiple equation testing strategy // Journal of Monetary Economics 38, 1996.

19. Chirinko R., H. Schaller. Why Does Liquidity Matter in Investment Equations? // Journal of Money, Credit and Banking. № 27, 1995.

20. Chan Louis K.C., Josef Lakonishok and Theodore Sougiannis. The stock market valuation of Research and Development Expenditures//The Journal of Finance, 2001,Vol. LVI, № 6. Dec.

21. Cleary Sean. The relationship between firm investment and financial status //The Journal of Finance, Vol. 54, № 2 , Apr., 1999.

22. Driver C., D. Moreton. The Influence of Uncertainty on UK Manufacturing Investment //Economic Journal, № 101,1991.

23. Fazzari S.,G. Hubbard B. Petersen. Financing constraints and corporate investment: response to Kaplan and Zingales // Working paper, January, 1996.

24. Ferderer J. The Impact of Uncertainty on Aggregate Investment Spending: An Empirical Analysis // Journal of Money, Credit and Banking, № 25, 1993.

25. Fuss Catherine, Philip Vermeulen. Firms' investment decisions in response to demand and price uncertainty // NBB Working Paper № 45, April 2004.

26. Gilchrist Simon, Charles P. Himmelberg, Gur Huberman. Do stock price bubbles influence corporate investment? // Journal of Monetary Economics 52, 2005. 
27. Gilchrist Simon, Charles P. Himmelberg. Evidence on the role of cash flow for investment //Journal of Monetary Economics, № 36, 1995.

28. Ghosal V., P. Loungani. Product Market Competition and the Impact of Price Uncertainty on Investment: Some Evidence From US Manufacturing Industries //Journal of Industrial Economics. № 44, 1996.

29. Gugler Klaus, Dennis C. Mueller and B. Burcin Yurtoglu, Corporate governance and the return on investment //Journal of Law and Economics, 2004, XLVII.

30. Goel Rajeev, K. Rati RamIrreversibility of R\&D investment and the adverse effect ofuncertainty: Evidence from the OECD countries //Economics Letters V. 71, 2001.

31. Gugler K., D. Mueller, B.Yurtoglu. Marginal Q, Tobin's Q, Cash flow and Investment //Southern Economic Journal,70 (3), 2004.

32. Heaton J. B. Managerial optimism and corporate finance // Financial Management, Vol. 31, 2002.

33. Hoshi T., A. Kashyap, D. Scharfstein. Corporate Structure, Liquidity, and Investment: Evidence from Japanese Industrial Groups // Quarterly Journal of Economics, № 6, 1991.

34. Hartman R. The effects of price and cost uncertainty on investment // Journal of Economic Theory, V 24, 1972.

35. Hayashi Fumio. Corporate finance side of the Q Theory of investment //Journal of Public Economics, № 27, 1985.

36. Hurn H. A., R. Wright. Geology or Economics? Testing Models of Irreversible Investment Using North Sea Oil Data // Economic Journal, № 104, 1994.

37. Jeon Yongil, Taekwon Kim, Stephen M. Miller. The Value of Waiting: Foreign Direct Investment with Uncertainty and Imperfect Local Knowledge // Review of Financial Economics, № 10, July, 2004.

38. Kaplan S., L. Zingales. Do Investment-Cash Flow Sensitivities Provide Useful Measures of Financing Constraints? //Quarterly Journal of Economics, № 112, 1997.

39. Kadapakkam Palani-Rajan, P.C. Kumar, Leigh A. Riddick. The impact of cash flows and firm size on investment: The international evidence // Journal of Banking \& Finance 22, 1998.

40. Kalckreuth Ulf von. Exploring the Role of Uncertainty for Corporate Investment Decisions in Germany // Discussion paper 5/00 Economic Research Group of the Deutsche Bundesbank, September, 2000.

41. KoganLeonidAsset prices and real investment // Journal of Financial Economics 73, 2004.

42. Lamont O. Cash flow and investment: evidence from internal capital markets // NBER, Working paper 5499, 1996. 
43. Leahy J., Whited T. The effect of uncertainty on investment: Some stylized factors //Journal of Money, Credit and Banking, № 37, Feb, 1996.

44. Malmendier Ulrike, Geoffrey Tate. Does Overconfidence Affect Corporate Investment? CEO Overconfidence Measures Revisited // European Financial Management, Vol. 11, № 5, 2005.

45. Mills Karen, Steven Morling and Warren Tease. The influence of financial factors on corporate investment //Economic Analysis Department, Reserve Bank of Australia, May, 1994.

46. Moyen N. Investment-cash flow sensitivities: constrained versus unconstrained firms // The Journal of finance, V.59, 2004.

47. Pennings Enrico. Taxes and stimuli of investment under uncertainty // European Economic Review, V. 44, 2000.

48. Pindyck Robert S. Irreversibility, Uncertainty, and Investment // Journal of Economic Literature, American Economic Association, Vol. 29 (3), September, 1991.

49. Pindyck Robert Irreversible Investment, Capacity Choice, and the Valuation of the Firm//American Economic Review, 79, December, 1988.

50. Rondi Laura, Alessandro Sembenelli, Giovanni Zanetti. Is excess sensitivity of investment to financial factors constant across firms? Evidence from panel data on Italian companies // Journal of Empirical Finance, № 1,1994.

51. Sterken Elmer, Robert Lensink, Hong Bo. Investment, cash flow and uncertainty: evidence for the Netherlands // University of Groningen, 10th International Conference on Panel Data, Berlin, July 5-6, 2002.

52. Schaller H. A. Re-examination of the Q Theory of Investment Using U.S. Firm Data //Journal of applied econometrics, Vol.5, № 4, Oct-Dec, 1990.

53. Shaanan Joseph Investment, irreversibility, and options: An empirical framework //Review of Financial Economics, V. 14, 2005.

54. Shiantarelli F., M. Devereux. Investment, financial factors and cash flow: evidence from UK panel data//Working paper 3116, NBER, 1989.

55. Tybout J. Credit Rationing and Investment Behavior in a Developing Country //Review of Economics and Statistics, № 65,1983.

56. Worthington P. Investment, Cash Flow, and Sunk Costs // Journal of Industrial Economics, № 43, 1995.

57. Дробышевский С., Радыгин А., Горшунов И., Изряднова О., Ильин А., Мальгинов Г., Турунцева М., Цухло С., Шкребела И.. Инвестиционное поведение российских предприятий. - М.: 2003 г.

58. Теплова Т. Инвестиционные рычаги максимизации стоимости компании. Практика российских предприятий. - М.: Вершина, 2007. 